\title{
North Atlantic climate control on plankton variability in the Balearic Sea, western Mediterranean
}

\author{
M. Luz Fernández de Puelles ${ }^{1}$ and Juan Carlos Molinero ${ }^{2}$ \\ Received 4 October 2006; revised 17 November 2006; accepted 16 January 2007; published 28 February 2007.
}

[1] We assessed interrelations between climatic, meteorological and hydrological factors in the Balearic Sea, and identified drivers of the abundance variability of planktonic copepods over the period 1994-2003. Temporal variability in the total abundance of copepods appears to be indicative of the southern spreading of the Northern Current, and therefore of meridional transport of water masses in the Balearic Sea. The results show that the largescale atmospheric variability in the North Atlantic Ocean acts as a main driver of regional meteorological variations and hydrographic patterns in the Balearic Sea area. The clearly most novel insight from this study is that the effects of the North Atlantic climate on hydrographic variability and the abundance of copepods in the studied area are noticeable at monthly scales. Thus, the North Atlantic climate influence on the structure and biogeochemical fluxes in the Western Mediterranean pelagic ecosystems deserve more attention that they have been received so far. Citation: Fernández de Puelles, M. L., and J. C. Molinero (2007), North Atlantic climate control on plankton variability in the Balearic Sea, western Mediterranean, Geophys. Res. Lett., 34, L04608, doi:10.1029/2006GL028354.

\section{Introduction}

[2] Climate variability plays a key role in the productivity of zooplankton and may affect fisheries at decadal and longer time-scales. Therefore it must be accounted for to implement sustainable management strategies [Parsons and Lear, 2001; Chavez et al., 2003]. Accordingly, an interest in the effects of climate fluctuations on ecological processes in oceans has emerged in the last decades, and numerous studies have shown that climate may have an important role-either directly or through its interactions with population densities [Peterson and Schwing, 2003; Hallet et al., 2004]. In the North Atlantic (NA), a major source of interannual variability in the atmospheric circulation is the North Atlantic Oscillation (NAO), which is related with the strength of the winter surface westerlies across the Ocean as far as Europe [Taylor, 2005]. The ecological consequences of the NAO have been noticed in freshwater, marine and terrestrial ecosystems of the North Atlantic region and surrounding continents [Ottersen et al., 2001; Sherman and Skjoldal, 2002]. Climatic forcing can alter structure, functioning and ultimately the energy pathway in food webs

\footnotetext{
${ }^{1}$ Centro Oceanográfico de Baleares, Instituto Español de Oceanografía, Palma de Mallorca, Spain.

${ }^{2}$ Station d'Hydrobiologie Lacustre, Institut National de la Recherche Agronomique, Thonon les Bains, France.
}

Copyright 2007 by the American Geophysical Union. 0094-8276/07/2006GL028354 and biogeochemical fluxes in the ocean. Hence, to forecast climate-driven changes a necessary step consists in identifying downscale pathways linking climate at large/regional scales and their effects on ecological processes at local ones [Pettorelli et al., 2005].

[3] In the Western Mediterranean (WM), the NA atmospheric circulation influences atmospheric pressure and ocean-atmosphere exchanges. Such climatic forcing substantially drives sea level changes [Tsimplis and Josey, 2001], water mass transport through the Corsica channel [Vignudelli et al., 1999], river flow [Trigo et al., 2004]; moisture transport [Fernández et al., 2003], and precipitation [Trigo et al., 2000]. It further appears as a large-scale driver of the long-term changes of zooplankton and ecological events, such as the timing of annual peaks of pelagic copepods in the Ligurian Sea NW Mediterranean [Molinero et al., 2005a, 2005b]. In the Balearic Sea (BS), Fernández de Puelles et al. [2004] showed that the mean annual abundance of zooplankton seems to be negatively correlated to the NAO. However, so far little has been done on the mediator factors linking local and large-scale processes and the response of plankton variability at lower time-scales (e.g. months). Here we applied multivariate statistical analysis to investigate how climatic variability governing the NA sector interacts with meteorological parameters and water temperature in the BS, and the effects on the abundance of pelagic copepods over a 10-year period, from 1994 to 2003. Pelagic copepods constitute the majority of the mesozooplankton biomass and their secondary production supports most of the food webs in the open sea directly affecting pelagic fish populations and the biological pump of carbon into the deep ocean [Ohman and Hirche, 2001]. They are therefore of primary interest to investigate potential bottom-up control on pelagic fish populations. In addition, the thermohaline circulation in the BS is governed by meridional exchanges between the cooler, more saline waters of the northern basin and the warmer, fresh waters of the southern (Algerian) basin of the WM [Pinot et al., 2002]. Hence, the BS appears as an ideal site to investigate the variability of thermohaline circulation, its relationship with large-scale climate forcing and their potential consequences on the structure of planktonic populations.

\section{Data and Methods}

[4] Standardised modes of low-frequency atmospheric variability in the Northern Hemisphere were used to assess climate forcing on the BS. We used the Northern Annular Mode (AO/NAO), the East Atlantic pattern (EA), the North Wall Gulf Stream Index (GSI), the East Atlantic Western Russian pattern (EA/WRUS) and the Northern Hemisphere Temperature (NHT), which affect climatic conditions in the 


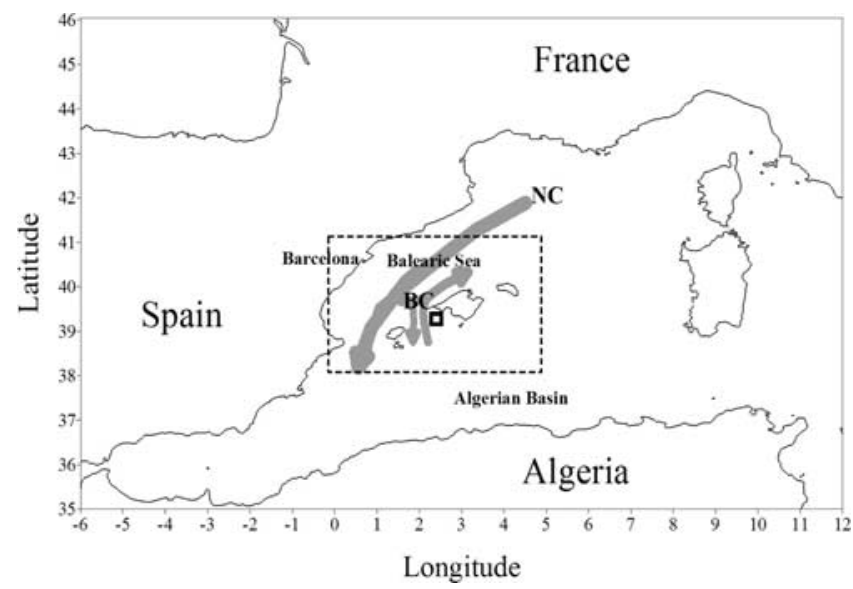

Figure 1. Western Mediterranean Basin and studied area (dotted rectangle: $0^{\circ} \mathrm{E}$ to $5^{\circ} \mathrm{E}$ and $38^{\circ} \mathrm{N}$ to $41^{\circ} \mathrm{N}$ ). The hydrographic station explored during the 10 -year monitoring period is indicated by the open square. Arrows indicate the average known flow pattern in the Balearic Sea (after Pinot et al. [2002], with permission from Elsevier). NC: Northern Current; BC: Balearic Current.

WM sector [Dünkeloh and Jacobeit, 2003]. The atmospheric variability in the BS was assessed by means of monthly anomaly fields of the follow meteorological parameters: surface air temperature, sea surface temperature, atmospheric sea level pressure, $500 \mathrm{hPa}$ geopotential height and precipitation records for the period 1950-2005 from the Climate Diagnostics Center (NCEP/NCAR) reanalysis fields [Kalney et al., 1996]. The selected area extends from $0^{\circ}$ to $5^{\circ} \mathrm{E}$ and from $38^{\circ}$ to $41^{\circ} \mathrm{N}$ (Figure 1).

[5] Hydrographic samples were recorded bi-weekly over a 10-year period (1994-2003) from 0 to $75 \mathrm{~m}$ depth in a monitoring station located in the southern shelf of Mallorca $\left(39^{\circ} 28^{\prime} 59 \mathrm{~N} ; 2^{\circ} 25^{\prime} 63 \mathrm{E}\right)$. The mean nitrates concentration on the water column was used as a proxy of nutrient availability for primary production. Instead of using surface water temperature which is highly influenced by the intermittency of local meteorological forcing, we used the values of the $75 \mathrm{~m}$ layer. Zooplankton samples were taken simultaneously at the same hydrographic station and cover the same timespan. Fernández de Puelles et al. [2004] give details of sampling analysis. Pelagic copepods denoted the majority of zooplankton biomass (>54\%), and their total abundance was used as a proxy of zooplankton interannual changes.

\section{Statistical Analysis}

[6] Temporal trends were removed by linear regression from the standardised monthly mean times-series, and residuals were used for analysis. Principal Component Analysis (PCA) was used to extract the main signals from monthly variability of NA and BS climates (period investigated 1950-2005), whereas Eigenvector filtering (EVF), also known as Principal Component Analysis of Processes [Ibanez and Etienne, 1992] was used to obtain the main temporal patterns of water temperature and pelagic copepods (period investigated 1994-2003). Briefly, the EVF corresponds to a PCA calculated on an autocovariance matrix based on the original series $z$ (the standardized series in this case) plus several copies of it, lagged by one time unit (equal to 1 month in our case). An objective number of $n$ lagged series corresponds to the number of lags at which autocorrelation of the original series first goes to zero [Ibanez and Etienne, 1992]. The resultant $n+1$ rank matrix, having as columns the original series plus the $n$ surrogates, is then submitted to a PCA to extract the principal modes of temporal variability. Afterwards, Canonical Correlation Analysis (CCA) was applied to quantify the degree of correlation between the monthly variability of the physical signals: large (NA climate), regional (BS meteorology) and local scale (water temperature), and the monthly abundance of copepods. Time series used for CCA corresponds to the three first principal components of each data set (mean $82 \%$ of variance, range of variance $68-97 \%$ ). A conservative alpha level of 0.01 was used to minimize the likelihood of committing a type I error.

\section{Results and Discussion}

[7] The mean annual changes of BS atmospheric variability was strongly correlated with the NA climate over the period 1950-2005 ( $r=0.72 ; p<0.001$, Figure 2$)$. Their pattern of interannual variability showed an upward shift starting during the early 1980 s, which corresponds to the dry and warm conditions that dominated the 1980s and most of the 1990s in the WM. CCA depicted significant links between the investigated climatic signals, and highlighted that the effect of the NA climate on the BS is noticeable over monthly scales, which has been elusive so far. In Table 1 we show highly significant correlations between the monthly means of NA climate, the atmospheric variability in the BS region, nitrates concentration and the total abundance of pelagic copepods. The results further reveal that the relationship between water temperature and pelagic copepods was stronger and takes place along the two first canonical correlations, which corresponds to different and independent channels. Such canonical correlations were

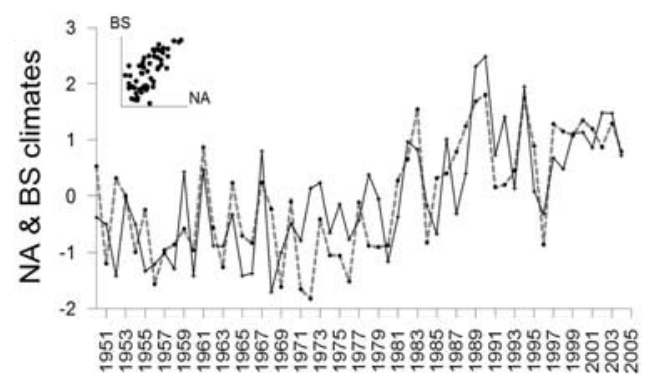

Figure 2. Interannual variability of the mean annual climatic signals used in this study as proxies of the North Atlantic (continuous line) and Balearic Sea (dotted line) climates over the 55-year period from 1950 to 2005. The signals are represented by the first principal components (PC1) of each data set. PC1 of North Atlantic climate represents $42 \%$ of the total variability, whereas $\mathrm{PC} 1$ of Balearic Sea climate represents $66 \%$ of the total variability. The Pearson correlation coefficient and the effective probability after correction for temporal autocorrelation are respectively $r=0.72$ and $p<0.001$. Left corner: Dispersion diagram of the relationship between the two variables. 
Table 1. First Canonical Correlation Coefficients Between Principal Components of North Atlantic Climate, Balearic Climate, Water Temperature, Nitrates and Total Abundance of Pelagic Copepods $^{\mathrm{a}}$

\begin{tabular}{|c|c|c|c|c|}
\hline & \multicolumn{2}{|c|}{ Monthly } & \multicolumn{2}{|c|}{ Winter } \\
\hline & $r$ & $p$ & $r$ & $p$ \\
\hline \multicolumn{5}{|c|}{ NA Climate } \\
\hline CCA1 NA climate - BS & 0.63 & 0.0001 & 0.70 & 0.0001 \\
\hline CCA1 NA climate - temperature & 0.59 & 0.0001 & 0.88 & 0.0001 \\
\hline CCA1 NA climate - nitrates & -0.41 & 0.01 & -0.44 & 0.01 \\
\hline CCA1 NA climate - copepods & -0.32 & 0.03 & -0.44 & 0.05 \\
\hline \multicolumn{5}{|c|}{ Regional Climate } \\
\hline CCA1 BS - temperature & 0.72 & 0.0001 & 0.75 & 0.0001 \\
\hline CCA1 BS - nitrates & -0.61 & 0.001 & -0.40 & 0.05 \\
\hline CCA1 BS - copepods & -0.56 & 0.0001 & -0.60 & 0.0001 \\
\hline \multicolumn{5}{|c|}{ Water Temperature } \\
\hline CCA1 temperature - nitrates & -0.53 & 0.001 & -0.60 & 0.001 \\
\hline CCA1 temperature - copepods & -0.73 & 0.0001 & -0.65 & 0.0001 \\
\hline CCA2 temperature - copepods & -0.32 & 0.001 & -0.51 & 0.001 \\
\hline
\end{tabular}

${ }^{\mathrm{a}} \mathrm{CCA}$ is canonical correlation coefficients, NA is North Atlantic climate, and BS is Balearic climate. Correlations were calculated on the complete time-series (monthly column), and also on period December-March (winter column). CCA reveals that water temperature and copepods are significantly related through two canonical correlations, which were driven by the first and second principal components, corresponding to the general trend and the seasonal variability, respectively. A conservative alpha level of 0.01 was used to minimize the likelihood of committing type I error when identifying links between climate and biological fields.

driven by PC1s (indicative of the long-term trend) and PC2s (indicative of the seasonal patterns) of each time series. This stresses the role temperature plays in the BS as a driver for biomass of pelagic copepods. CCA further reveals that the NA climatic forcing on the BS atmospheric variability is stronger in wintertime, as showed by the higher correlations obtained when using data from December to March (Table 1). It is also noticeable a general increase in correlations coefficients between the atmospheric variability and water temperature in the BS.

[8] CCA has been widely used as an analysis and downscaling technique in many geophysical fields including meteorology and oceanography [von Storch and Zwiers, 1999; Matulla et al., 2003]. In marine research it has been applied to identify and quantify the association between the variability in the spatial patterns of cod recruitment and climate in the North and Barents Seas [Sirabella et al., 2001], as well as climatic effects on zooplankton long-term changes in the Ligurian Sea [Molinero et al., 2005a]. Here, CCA reveals a close connection between the NA climate and water temperature in the BS, as a mediator factor shaping the variability of pelagic copepods, and confirm the NA effect on the WM. Indeed, Orfila et al. [2005] have recently shown signatures of NA teleconnections in the sea level anomaly field of the Ligurian Sea, NW Mediterranean. Moreover, by truncating the monthly time-series of climatic indices we obtained the main pattern of climate forcing affecting the atmospheric variability in the BS. Such temporal pattern integrates the NA climate effects on the studied area and appears therefore as a valuable proxy for assessing hydrological variability and climate-driven ecological changes in this region (e.g. NAO - BS atm. variability: $r=0.57 ; p<0.05$; NA climate $-\mathrm{BS}$ atm. variability: $r=0.72 ; p<0.001)$. Furthermore, winter emerges as the critical time window through which the forcing of the NA climate explains most of the zooplankton variability in the BS. A plausible ecological explanation is that in winter, the coupled ocean-atmosphere system is most active and strongly affects the atmospheric variability in the NA. Low anomalies of NA climate are associated to a stronger mixing of the water column in the WM [Demirov and Pinardi, 2002] and thus to the high availability of nutrients for phytoplankton blooms. Accordingly, we found a significant relationship between NA climate variability and a proxy of nutrient availability for primary production (e.g. nitrates concentration) (see Table 1). Therefore, one of the factors favouring higher (lower) abundances of copepods during low (high) NA anomalies is likely related to potential higher (lower) phytoplankton abundances favoured by the higher (lower) nutrient availability. Fernández de Puelles et al. [2004] have shown an inverse relationship between nitrates concentration and water temperature at yearly scales $(p<0.01)$. Here we have shown that such relationship when analyzed at monthly scales remains significant $(r=-0.53 ; p<0.001)$ and it increases when considering only winter months $(r=-0.60 ; p<0.001)$. Moreover, it is not excluded that the variability in abundance of copepods may be also related to the water mass transport in the BS. In winter, a marked southern spreading of large volume of northern waters $(1.3 \mathrm{~Sv})$ entrained by the Northern current (NC) has been noticed in the BS [Pinot et $a l ., 2002]$. The intensity of the current decrease in the latespring and reach the lowest values in summer, when the amount of the transport fall to $<0.05 \mathrm{~Sv}$. Thus, the variability of the NC, linked to the NA climate forcing, drives the spread of northern waters (cold and rich) into the BS [Pinot et al., 2002]. The stronger the atmospheric forcing during winter (low NA climate anomalies) the intense the winter mixing, which may reach deep waters and enhance productivity in northern areas such as the Gulf of Lions and therefore favor a southern spread of rich waters [Estrada et al., 1985], which can be also reflected in the increase of nutrients availability (e.g. nitrates) for primary production in the BS area. The NA atmospheric forcing has been also shown in the dynamics of the water transport in the Corsica Channel (WM) and its effects noticed in the NC [Vignudelli et al., 1999]. Hence, the abundance of copepods is likely favoured by the increased productivity associated to the low NA climate anomalies, as well as through increased advection from the North of the WM into the BS.

[9] The interactions emerged from these results indicate a close connection between the hydrographic variability (i.e. water temperature) in the $\mathrm{BS}$ and the concentration of nitrates and the total abundance of copepods. This was clearly illustrated by considering water temperature anomalies corresponding to the strong values of NA climate anomalies (higher or lower than 1 standard deviation) (Figures $3 \mathrm{a}$ and $3 \mathrm{~b})$. Strong values ( $>1$ standard deviation) have been suggested as discriminating thresholds for the atmospheric circulation in the NW Mediterranean region [Hurrell, 1995; Vignudelli et al., 1999]. Therefore these results suggest a bottom-up control on the abundance of copepods, likely promoted by the lower (higher) mixing and high (cold) temperatures related to high (low) NA climate anomalies, which would impair productivity locally, as 

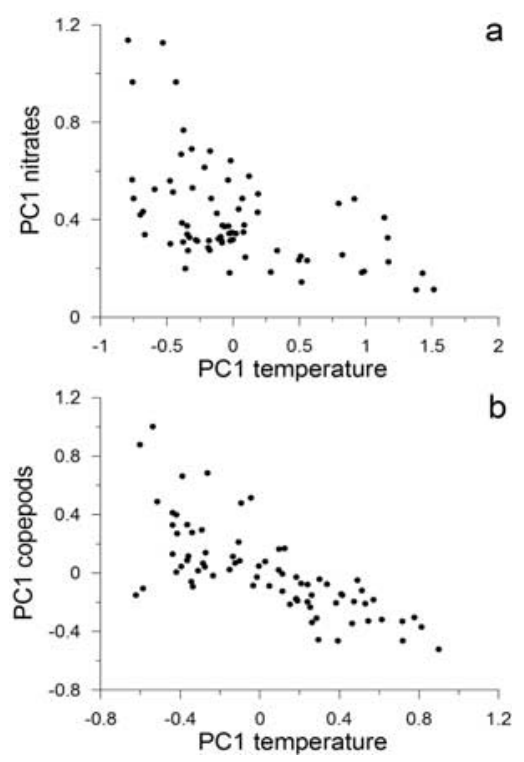

Figure 3. (a) Dispersion diagram in the plane of $\mathrm{PC} 1 \mathrm{~s}$ of temperature ( $35 \%$ of the total variance) and nitrates $(55 \%$ of the total variance). The Pearson correlation coefficient and the effective probability after correction for temporal autocorrelation are respectively $r=-0.51$ and $p<0.001$. (b) Dispersion diagram in the plane of $\mathrm{PC} 1 \mathrm{~s}$ of temperature (35\% of the total variance) and copepods $(33 \%$ of the total variance). The Pearson correlation coefficient and the effective probability after correction for temporal autocorrelation are respectively $r=-0.72$ and $p<0.001$. Observations used correspond to values related to high anomalies ( $>1$ standard deviation) of the North Atlantic climate variability.

suggested by the link between nitrates concentration and NA climate, and then allow to a less food availability for copepods. However, we cannot exclude that during high NA anomalies (higher water temperature) copepods undergo a higher predation pressure by gelatinous carnivores (i.e. medusa, siphonophores) whose abundances strongly increase during warm periods in the WM [Molinero et al., 2005a], although this hypothesis should be confirmed by adequate data.

[10] The clearly most novel insight from our study is that the influence of the NA climate is noticeable on the monthly scale in both environmental conditions (i.e. water temperature, nitrates) and the total abundance of pelagic copepods. Thus, water temperature changes appeared related to the intensity of the southern spread of the NC during high/low NA climate anomalies as showed elsewhere [Pinot et al., 2002]. According to Molinero et al. [2005a, 2005b], we stress that the observed zooplankton abundance changes are part of a larger and long term variability linking the pelagic dynamics in the NW Mediterranean and the Oceanatmospheric system in the NA Ocean. Moreover, as the abundance of copepods directly affect pelagic fish populations and the biological pump of carbon into the deep ocean [Ohman and Hirche, 2001] it is ecologically plausible that the NA climatic control on copepods also affect the vertical particle flux and carbon transfer rates from upper to deeper layers. Therefore, a thorough understanding of the WM ecosystem functioning and its temporal variability requires the accurate assessment of the NA effects on primary and secondary production. Particularly, climate forcing needs to be fully explored on the other pelagic functional groups in order to take into account their responses in the building of biogeochemical models of the WM. Hence, the NA climate effects on the food-webs dynamics and biogeochemical fluxes in the WM pelagic ecosystems deserve more attention that they have been received so far.

[11] Acknowledgments. This research has been founded by the Instituto Español de Oceanografia (IEO) through the project Oceanographic Time Series in the Spanish coast carried out by the Centro Oceanografico de Baleares. We thank Joaquim Dippner and two anonymous reviewers for their thoughtful comments, which improved the manuscript. NCEP Reanalysis data were provided by the NOAA-CIRES ESRL/PSD Climate Diagnostics branch, Boulder, Colorado, USA, from their Web site at http:// www.cdc.noaa.gov/. We thank the Climatic Research Unit (CRU), the Climatic Prediction Center NOAA, and A. Taylor for make available climatic indices. The authors are grateful to the crew of the R/V Odón de Buén, captain A.P. Sanchez and technicians M. Serra and T. Salamanca. We are thankful to L. Vicente for help in zooplankton counting.

\section{References}

Chavez, F. P., J. Ryan, E. Lluch-Cota, and M. Ñiquen (2003), From anchovies to sardines and back: Multidecadal change in the Pacific Ocean, Science, 299, 217-221.

Demirov, E., and N. Pinardi (2002), Simulation of the Mediterranean Sea circulation form 1979 to 1993. part I: The interannual variability, J. Mar. Sci., 33-34, 23-50.

Dünkeloh, A., and J. Jacobeit (2003), Circulation dynamics of the Mediterranean precipitation variability $1948-1998$, Int. J. Climatol., 23, $1843-1866$

Estrada, M., F. Vives, and M. Alcaraz (1985), Life and Production in the Open Sea, 150-200 pp., Elsevier, New York.

Fernández, J., J. Saez, and E. Zorita (2003), Analysis of wintertime atmospheric moisture transport and its variability over southern Europe in the NCEP reanalysis, Clim. Res., 23, 195-215.

Fernández de Puelles, M. L., J. Valencia, and L. Vicente (2004), Zooplankton variability and climatic anomalies from 1994 to 2001 in the Balearic Sea (western Mediterranean), ICES J. Mar. Sci., 61, 492-500.

Hallet, T. B., T. Coulson, J. G. Pilkington, T. H. Clutton-Brock, J. M. Pemberton, and B. T. Grenfell (2004), Why large-scale climate indices seem to predict ecological processes better than local weather, Nature, 430, $71-75$.

Hurrell, J. W. (1995), Decadal trends in the North Atlantic Oscillation: Regional temperature and precipitation, Science, 269, 276-279.

Ibanez, F., and M. Etienne (1992), Le filtrage des series chronologiques par l'analyse en composant principales de processuss (ACPP), J Rech. Oceanogr., 16, 66-72.

Kalney, E., et al. (1996), The NCEP/NCAR 40-year reanalysis project, Bull. Am. Meteorol. Soc., 77, 437-471.

Matulla, C., H. Scheifinger, A. Menzel, and E. Koch (2003), Exploring two methods for statistical downscaling on central European phenologies time series, Int. J Biometeorol., 48, 56-64.

Molinero, J. C., F. Ibanez, E. Buecher, S. Souissi, and P. Nival (2005a), North Atlantic climate and northwestern Mediterranean plankton variability, Limnol. Oceanogr., 50, 1213-1220.

Molinero, J. C., F. Ibanez, S. Souissi, M. Chifflet, and P. Nival (2005b), Phenological changes in the northwestern Mediterranean copepods Centropages typicus and Temora stylifera linked to climate forcing, Oecologia, $145,640-649$.

Ohman, M. D., and H. J. Hirche (2001), Density-dependent mortality in an oceanic copepod population, Nature, 412, 638-641.

Orfila, A., A. Alvarez, J. Tintoré, A. Jordi, and G. Basterretxea (2005), Climatic teleconnections at monthly scales in the Ligurian Sea inferred form satellite data, Prog. Oceanogr., 66, 157-170.

Ottersen, G., B. Planque, A. Belgrano, E. Post, C. Reid, and N. Stenseth (2001), Ecological effects of the North Atlantic Oscillation, Oecologia, $128,1-14$.

Parsons, L. S., and W. H. Lear (2001), Climate variability and marine ecosystems impacts: A North Atlantic perspective, Prog. Oceanogr., 49, $167-188$.

Peterson, W. T., and F. B. Schwing (2003), A new climate regime in northeast Pacific ecosystems, Geophys. Res. Lett., 30(17), 1896, doi:10.1029/ 2003GL017528. 
Pettorelli, N., A. Mysterud, N. G. Yoccoz, R. Langvatn, and N. C. Stenseth (2005), Importance of climatological downscaling and plant phenology for red deer in heterogeneous landscapes, Proc. R. Soc., Ser. B, 272, $2357-2364$

Pinot, J. M., J. L. Lopez-Jurado, and M. Riera (2002), The CANALES experiment (1996-1998), Interannual, seasonal, and mesoscale variability of the circulation in the Balearic Channels, Prog. Oceanogr., 55, $335-370$.

Sherman, K., and H. R. Skjoldal (Eds.) (2002), Large Marine Ecosystems of the North Atlantic: Changing States and Sustainability, 449 pp., Elsevier, New York.

Sirabella, E. A., A. Giuliani, A. Colosimo, and J. W. Dippner (2001) Breaking down the climatic effects on cod recruitment by principal component analysis and canonical correlation, Mar. Ecol. Prog. Ser., 216, $213-222$.

Taylor, A. H. (2005), A model of variations in the North Atlantic Oscillation, Geophys. Res. Lett., 32, L24713, doi:10.1029/2005GL023792.

Trigo, I., T. Davies, and G. Bigg (2000), Decline in the Mediterranean rainfall caused by weakening of Mediterranean cyclones, Geophys. Res. Lett., 27, 2913-2916.
Trigo, R. M., D. Pozo-Vazquez, T. Osborn, Y. Castro-Diez, S. GamizFortis, and M. J. Esteban-Parra (2004), North Atlantic Oscillation influence on precipitation, river flow and water resources in the Iberian Peninsula, Int. J. Climatol., 24, 925-944.

Tsimplis, M., and S. A. Josey (2001), Forcing on the Mediterranean Sea by atmospheric oscillations over the North Atlantic, Geophys. Res. Lett., 28, $803-806$.

Vignudelli, S., G. P. Gasparini, M. Astraldi, and M. E. Schiano (1999), A possible influence of the North Atlantic Oscillation on the circulation of the western Mediterranean Sea, Geophys. Res. Lett., 26, 623-626.

von Storch, H., and F. W. Zwiers (1999), Statistical Analysis in Climate Research, 484 pp., Cambridge Univ. Press, New York.

M. L. Fernández de Puelles, Centro Oceanográfico de Baleares, Instituto Español de Oceanografía, Muelle de Poniente s/n, E-07015-Palma de Mallorca, Baleares, Spain. (mluz.fernandez@ba.ieo.es)

J. C. Molinero, Station d'Hydrobiologie Lacustre, Institut National de la Recherche Agronomique, BP 511, 75 avenue de Corzent, F-74203 Thonon les Bains cedex, France. (molinero@thonon.inra.fr) 